\title{
Immunohistochemical expression of fibronectin and C5b-9 in the myocardium in cases of fatal ethanol intoxication
}

\author{
Tony Fracasso $\cdot$ Heidi Pfeiffer $\cdot$ Helga Köhler • \\ Sonja Wieseler • Simon David Hansen • Lena Jentgens • \\ Cristina Sauerland $\cdot$ Andreas Schmeling
}

Received: 1 September 2010 /Accepted: 3 January 2011 /Published online: 14 January 2011

(C) Springer-Verlag 2011

\begin{abstract}
Data from the literature indicate that the pulmonary pressure rises in cases of ethanol intake. We have recently proposed a method for the detection of prevalent right ventricular damage in cases of fatal pulmonary thromboembolism and pulmonary fat embolism. In the present study, we compared the expression of the antibodies against fibronectin and C5b-9 in 19 cases of lethal alcohol intoxications (study group: 5 females, 14 males, mean age 46 years, mean blood ethanol concentration $3.5 \%$, min. $2.11 \%$, max. $5.31 \%$ ) to a group of 26 cases of fatal pulmonary thromboembolism (PE; group 2: 16 females, 10 males, mean age 56 years). Moreover, a group of 15 cases of hanging (group 3: 5 females, 10 males, mean age 50 years) as well as a group of 18 cases of myocardial infarction (group 4: 5 females, 13 males, mean age 61 years) were investigated as examples of typical cardiac damage due to global hypoxia during agony and ischemic damage,
\end{abstract}

Electronic supplementary material The online version of this article (doi:10.1007/s00414-011-0547-8) contains supplementary material, which is available to authorized users.

T. Fracasso $\cdot$ H. Pfeiffer $\cdot$ H. Köhler $\cdot$ S. Wieseler $\cdot$ S. D. Hansen $•$

L. Jentgens $\cdot$ A. Schmeling

Institute of Legal Medicine, University Hospital Münster,

Röntgenstr. 23,

48149 Münster, Germany

T. Fracasso $(\square)$

University Center of Legal Medicine,

Rue Michel-Servet 1,

1211 Geneva, Switzerland

e-mail: Tony.Fracasso@hcuge.ch

C. Sauerland

Institute of Biostatistics and Clinical Research,

University Hospital Münster,

Domagkstr. 9 ,

48149 Münster, Germany respectively. The results of this study show that fresh cardiac damage can be detected at both ventricles in cases of fatal ethanol intoxication with the antibody against fibronectin. The damage is prevalently localised at the right ventricle (RV), as already observed in cases of acute pulmonary hypertension determining right heart failure. The degree of damage at the RV in cases of ethanol intoxications is lower than the one observed in cases of fatal PE.

Keywords Right heart failure - Ethanol intoxication . Fibronectin $\cdot$ C5b-9 $\cdot$ Acute pulmonary hypertension

\section{Introduction}

Ethanol is one of the most common substances of abuse, contributing to numerous accidental deaths as a concomitant factor, i.e. in cases of traffic accidents, falls, drowning or hypothermia [1]. Ethanol is also responsible for numerous fatal intoxications; in such cases, it is generally accepted that the death is related to its effects on the central nervous system where it is particularly effective because of its high lipophilicity [2]. At this level, ethyl alcohol at high doses leads to the inhibition of the respiratory centres with progressive global hypoxia and affects the circulatory centres with progressive heart failure [2-4].

An important but not well-known effect of ethanol on the cardiovascular system is the increase of the pulmonary pressure. In 1907, Dixon [5] was the first to describe this phenomenon after alcohol administration in an animal model. He suggested that ethanol has an effect on the medulla and the basal ganglia with consequent dilatation of the skin vessels and constriction of the splanchnic ones. Doeckel et al. [6] made similar observations in anesthetized 
mongrel dogs under the effects of ethanol and suggested a selective increase in pulmonary vascular resistance. Ethanol would act primarily as a potentiator of the hypoxia-induced pulmonary vasoconstriction, as suggested by the fact that pulmonary vascular resistance could be abolished by the administration of a high oxygen mixture in the inspired air. Also, a group of Finnish medicolegal researchers focused on the effects of ethanol on the pulmonary circle: Kettunen et al. [7] reported a linear correlation between increasing blood ethanol concentration and increased pulmonary arterial pressure due to increased pulmonary arterial resistance. In a later study [8], the same group reported depressed right ventricular activity due to increased right ventricular afterload by constricting pulmonary arteries in dogs with low blood ethanol levels. An ethanol-induced pulmonary vasoconstriction was also observed in lambs and rats [9]: on occasion of this research, the authors evaluated the possible influence of ethanol-induced global hypoxia in the determination of pulmonary artery constriction and further discussed the potential role of locally produced mediators such as histamines or leukotrienes from pulmonary mast cells. Finally, a study conducted in six voluntary healthy physicians demonstrated a rise in pulmonary vascular resistance and pressure with diminished preload of the left ventricle after ingestion of $0.5 \mathrm{~g} / \mathrm{Kg}$ ethanol, corresponding to peak blood ethanol concentrations between $0.5 \%$ and $0.7 \%$ [ [10].

We have recently proposed an immunohistochemical method for the detection of prevalent ischemic damage at the right ventricle, determining acute right ventricular failure and death in cases of severe fat embolism and pulmonary thromboembolism [11, 12].

On the basis of those investigations and on the information from the literature, with the present study, we wanted to evaluate:

1 Whether fresh cardiac damage can be detected in immunohistochemistry with the antibodies against fibronectin and C5b-9 in the myocardium in cases of fatal ethanol intoxication.

2 Whether the reaction pattern of those two markers in such cases is similar to the one observed in cases of acute fatal pulmonary hypertension.

\section{Materials and methods}

\section{Investigated cases}

We compared 19 cases of fatal alcohol intoxications (study group: 5 females, 14 males, mean age 46 years, mean blood ethanol concentration $3.5 \%$, min. $2.11 \%$, max. $5.31 \%$ ) to a group of 26 cases of fatal pulmonary thromboembolism (PE; group 2: 16 females, 10 males, mean age 56 years) in which the acute increase of pulmonary pressure determined right ventricular failure. Moreover, a group of 15 cases of hanging (group 3: 5 females, 10 males, mean age 50 years) as well as a group of 18 cases of myocardial infarction (group 4: 5 females, 13 males, mean age 61 years) were investigated as examples of typical cardiac damage due to global hypoxia during agony and ischemic damage, respectively. The cases were collected at the Institute of Legal Medicine of the University Hospital in Münster, Germany and investigated retrospectively. In each case, information about the circumstances of death as well as autopsy records were available. An overview of the investigated cases is given in Tables 1 and 2, ESM 1 and ESM 2.

Immunohistochemical reactions

In each case, immunohistochemical reactions with the antibodies fibronectin (Polyclonal Rabbit Anti-Human, DAKO Deutschland GmbH, Hamburg, Germany) and C5b-9 (Monoclonal Mouse Anti-Human, DAKO Deutschland $\mathrm{GmbH}$, Hamburg, Germany) of both cardiac ventricles (free wall of the right ventricle (RV), anterior and/or posterior wall of the left ventricle (LV)) were prepared as described elsewhere $[13,14]$. A blind investigation of the slides was performed by two different observers with final consensual evaluation. The positive reactions were semiquantitatively classified as follows (Fig. 1) [11]:

Level 0 Negative

Level 1 Single cell necrosis

Level 2 Group cell necrosis

Level 3 Diffuse necrosis

Statistical analysis

The level of necrosis in each ventricle for each antibody was compared to the corresponding value of the groups 2,3 and 4 (level of necrosis RV fibronectin study group versus level of necrosis RV fibronectin groups 2, 3 and 4; level of necrosis RV C5b-9 study group versus level of necrosis RV C5b-9 groups 2, 3 and 4; level of necrosis LV fibronectin study group versus level of necrosis LV fibronectin groups 2, 3 and 4; level of necrosis LV C5b-9 study group versus level of necrosis RV C5b-9 groups 2, 3 and 4).

The difference of the level of the necrosis between right and left ventricle was calculated in each case $(\Delta=$ level necrosis RV-level necrosis LV) with both antibodies. A comparison of these differences between the study group and groups 2, 3 and 4 was performed. 
Table 1 Study group, fatal ethanol intoxications with bac $>2 \%$ ( $N=19 ; 5$ females, 14 males, mean age 46 years $)$

\begin{tabular}{|c|c|c|c|c|c|c|c|c|c|c|}
\hline ID & Sex & Age & Bec \%o & Uec \%o & RV fibronectin & LV fibronectin & $\Delta$ fibronectin & RV C5b-9 & LV C5b-9 & $\Delta \mathrm{C} 5 \mathrm{~b}-9$ \\
\hline 1 & $\mathrm{~m}$ & 46 & 2.67 & 3.87 & 2 & 0 & 2 & 1 & 0 & 1 \\
\hline 2 & $\mathrm{f}$ & 32 & 5.12 & 6.20 & 2 & 1 & 1 & 0 & 0 & 0 \\
\hline 3 & $\mathrm{~m}$ & 46 & 3.84 & 4.73 & 2 & 1 & 1 & 0 & 0 & 0 \\
\hline 4 & $\mathrm{~m}$ & 42 & 4.47 & 5.82 & 2 & 1 & 1 & 0 & 0 & 0 \\
\hline 5 & $\mathrm{~m}$ & 44 & 3.59 & 5.15 & 2 & 0 & 2 & 0 & 0 & 0 \\
\hline 6 & $\mathrm{~m}$ & 42 & 3.22 & 4.26 & 3 & 1 & 2 & 0 & 0 & 0 \\
\hline 7 & $\mathrm{f}$ & 46 & 3.28 & 4.09 & 1 & 0 & 1 & 0 & 0 & 0 \\
\hline 8 & $\mathrm{~m}$ & 26 & 2.11 & - & 2 & 0 & 2 & 0 & 0 & 0 \\
\hline 9 & $\mathrm{~m}$ & 59 & 3.19 & - & 2 & 2 & 0 & 0 & 0 & 0 \\
\hline 10 & $\mathrm{f}$ & 53 & 3.4 & 3.77 & 3 & 2 & 1 & 0 & 0 & 0 \\
\hline 11 & $\mathrm{f}$ & 50 & 3.35 & - & 2 & 1 & 1 & 0 & 0 & 0 \\
\hline 12 & $\mathrm{~m}$ & 69 & 2.79 & 3.58 & 2 & 0 & 2 & 0 & 0 & 0 \\
\hline 13 & $\mathrm{~m}$ & 27 & 4.17 & - & 0 & 0 & 0 & 0 & 0 & 0 \\
\hline 14 & $\mathrm{~m}$ & 44 & 3.50 & - & 2 & 0 & 2 & 0 & 0 & 0 \\
\hline 15 & $\mathrm{f}$ & 61 & 3.05 & - & 3 & 0 & 3 & 0 & 0 & 0 \\
\hline 16 & $\mathrm{~m}$ & 46 & 3.62 & 4.7 & 0 & 0 & 0 & 0 & 0 & 0 \\
\hline 17 & $\mathrm{~m}$ & 69 & 3.40 & 3.85 & 1 & 0 & 1 & 0 & 0 & 0 \\
\hline 18 & $\mathrm{~m}$ & 29 & 5.31 & 5.33 & 1 & 0 & 1 & 0 & 0 & 0 \\
\hline 19 & $\mathrm{~m}$ & 42 & 2.7 & 4.06 & 0 & 0 & 0 & 0 & 0 & 0 \\
\hline
\end{tabular}

Dashes indicate that urine could not be collected at autopsy

Statistical analyses were performed using SAS 9.2 (SAS Institute Inc., Cary, NC).

Fisher's exact test was used for all comparisons between the investigated groups. The result was considered significant in case of the two-sided $p<0.05$.

\section{Results}

The comparison of the reaction with the antibody against fibronectin at the RV showed a similar expression of the antibody in cases of ethanol intoxications, myocardial infarctions and cases of hanging. A statistically significant difference was observed instead in the comparison of the study group with the group PE $(p=0.0038)$. In detail, in the study group, three cases did not show positive reactions with fibronectin at the RV, three showed single cell necrosis, and 10 group cell necrosis. Diffuse necrosis was not observed at the RV in this group. In group 2, 12 cases showed group cell necrosis and 14 diffuse necrosis. The right ventricle was quantitatively much more affected in group 2 than in the study group.

The comparison of the reaction with the antibody against fibronectin at the LV showed a prevalent damage at this ventricle in cases of myocardial infarction $(p<0.0001)$ compared to ethanol intoxications. Similarly, the comparison with the group hanging showed a major involvement of this ventricle in the hanging group; however, with a significance at the limit of the stated significance level $(p=0.0532)$. The comparison with the group PE shows a similar expression of this antibody in the two groups.

The comparison of the parameter $\Delta$ fibronectin showed a statistically different distribution in cases of ethanol intoxications compared to myocardial infarctions $(p<$ $0.0001)$ and to cases of hanging $(p=0.0143)$. The comparison with the group PE showed a similar distribution of this parameter in the two groups.

With the antibody against C5b-9, single cell necrosis was observed once at the RV in cases of ethanol intoxications and twice in cases of myocardial infarction. Group cell necrosis was observed in six cases of myocardial infarction at the LV. Diffuse necrosis was observed once at $\mathrm{LV}$ in cases of myocardial infarction. In cases of PE, the reaction against the terminal complement complex C5b-9 turned out positive in eight cases at the RV (level 1 was observed in five cases, level 2 in three cases) and was constantly negative at the LV.

\section{Discussion}

When the right ventricular pressure is severely increased, the oxygen demand of the RV is augmented while the right coronary artery flow is reduced as it mainly occurs 
Table 2 Cases of fatal pulmonary thromboembolism ( $N=26$; 16 females, 10 males, mean age 56 years)

\begin{tabular}{|c|c|c|c|c|c|c|c|c|}
\hline ID & Sex & Age & RV fibronectin & LV fibronectin & $\Delta$ fibronectin & RV C5b-9 & LV C5b-9 & $\Delta \mathrm{C} 5 \mathrm{~b}-9$ \\
\hline 1 & $\mathrm{f}$ & 71 & 3 & 1 & 2 & 2 & 0 & 2 \\
\hline 2 & $\mathrm{~m}$ & 44 & 3 & 2 & 1 & 0 & 0 & 0 \\
\hline 3 & $\mathrm{f}$ & 32 & 2 & 0 & 2 & 0 & 0 & 0 \\
\hline 4 & $\mathrm{f}$ & 80 & 3 & 1 & 2 & 1 & 0 & 1 \\
\hline 5 & $\mathrm{f}$ & 51 & 2 & 2 & 0 & 0 & 0 & 0 \\
\hline 6 & $\mathrm{f}$ & 22 & 2 & 1 & 1 & 0 & 0 & 0 \\
\hline 7 & $\mathrm{~m}$ & 55 & 2 & 1 & 1 & 1 & 0 & 1 \\
\hline 8 & $\mathrm{~m}$ & 65 & 3 & 2 & 1 & 0 & 0 & 0 \\
\hline 9 & $\mathrm{f}$ & 49 & 3 & 0 & 3 & 0 & 0 & 0 \\
\hline 10 & $\mathrm{f}$ & 51 & 3 & 1 & 2 & 0 & 0 & 0 \\
\hline 11 & $\mathrm{f}$ & 49 & 3 & 0 & 3 & 1 & 0 & 1 \\
\hline 12 & $\mathrm{f}$ & 72 & 2 & 1 & 1 & 1 & 0 & 1 \\
\hline 13 & $\mathrm{~m}$ & 83 & 2 & 1 & 1 & 0 & 0 & 0 \\
\hline 14 & $\mathrm{f}$ & 80 & 3 & 1 & 2 & 0 & 0 & 0 \\
\hline 15 & $\mathrm{~m}$ & 72 & 3 & 0 & 3 & 0 & 0 & 0 \\
\hline 16 & $\mathrm{~m}$ & 43 & 3 & 1 & 2 & 0 & 0 & 0 \\
\hline 17 & $\mathrm{f}$ & 84 & 3 & 2 & 1 & 0 & 0 & 0 \\
\hline 18 & $\mathrm{f}$ & 75 & 3 & 1 & 2 & 0 & 0 & 0 \\
\hline 19 & $\mathrm{f}$ & 48 & 2 & 0 & 2 & 2 & 0 & 0 \\
\hline 20 & $\mathrm{~m}$ & 23 & 3 & 3 & 0 & 1 & 0 & 1 \\
\hline 21 & $\mathrm{f}$ & 22 & 2 & 2 & 0 & 2 & 0 & 2 \\
\hline 22 & $\mathrm{~m}$ & 38 & 3 & 1 & 2 & 0 & 0 & 0 \\
\hline 23 & $\mathrm{f}$ & 87 & 2 & 1 & 1 & 0 & 0 & 0 \\
\hline 24 & $\mathrm{f}$ & 82 & 2 & 0 & 2 & 0 & 0 & 0 \\
\hline 25 & $\mathrm{~m}$ & 31 & 2 & 0 & 2 & 0 & 0 & 0 \\
\hline 26 & $\mathrm{~m}$ & 57 & 2 & 1 & 1 & 0 & 0 & 0 \\
\hline
\end{tabular}

during diastole. Moreover, during RV dilatation, the interventricular septum shifts toward the LV reducing the septal-to-lateral dimension of this chamber. Leftward septal shift results in mechanical stiffening of the interventricular septum, reducing LV compliance [15, 16] and determining lower LV output with lower coronary perfusion. The combination of increased demand and decreasing blood flow determines ischemic damage [17], primarily occurring in the sub-endocardial regions [18, 19]. Such damage is responsible for the right ventricular failure that occurs in cases of pulmonary thromboembolism and severe pulmonary fat embolism.

The immunohistochemical markers whose expression was investigated in this study were chosen because they are known to react in cases of early myocardial ischemia, and they allow an easy detection of the damage even in cases of single cell necrosis or of necrosis of little groups of cells [20].

In cases of ethanol intoxications, fresh cardiac damage could be detected with the antibody fibronectin at both ventricles. If compared to the distribution observed in cases of myocardial infarction and hanging, we observed that the damage is prevalently localised at the right ventricle, as well demonstrated by the comparison of the $\Delta$ values. This means that in cases of ethanol intoxication, fresh cardiac damage is distributed differently from cases in which cardiac ischemia or global hypoxia occurs: in these groups, in fact, the damage is mostly localised at the LV or equally distributed at the two chambers. It is worth mentioning that in a similar study, in which the cardiac damage in cases of cardiac infarction and ethanol intoxication were compared, Kapustin [21] could not detect fresh damage of the cardiomyocytes in the ethanol group in conventional histology.

For what concerns the comparison with the group of $\mathrm{PE}$, our results show that the degree of damage at the right ventricle in the second group is much higher than in the study group. The distribution of the damage is, instead, similar in both groups as shown by the comparisons of the delta value and the damage at the LV. This result corresponds to the literature describing 

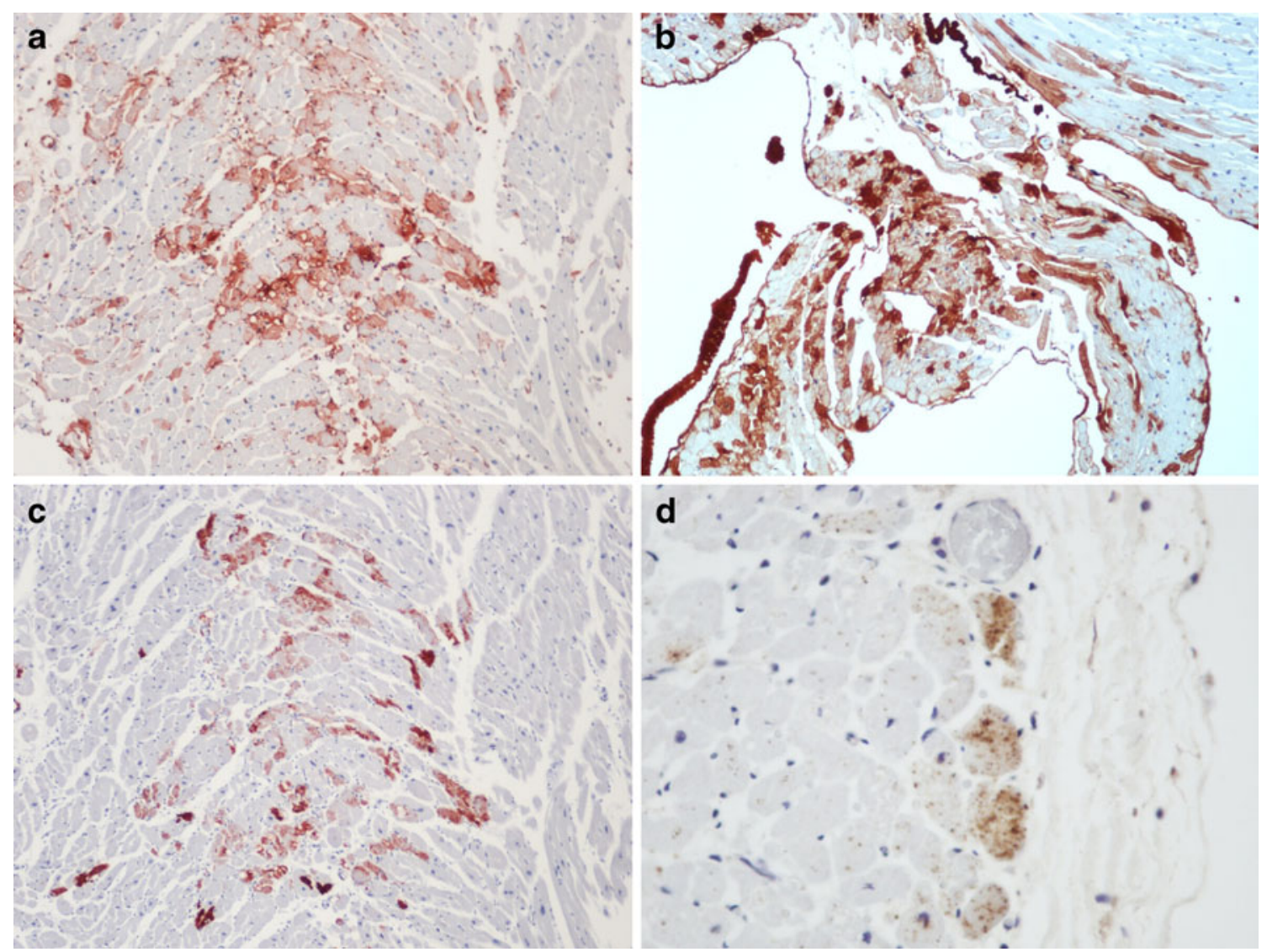

Fig. 1 a, b Exemplarily expression of the marker fibronectin in a case of fatal alcohol intoxication (a, RV grade 2, X100) and pulmonary thromboembolism (b, RV grade 3,100X). c Immunohistochemical reaction with the antibody against the terminal complement complex C5b-9 in case of PE (RV grade 2, x100). d Fine granulations were occasionally observed in every group (in the picture, RV x400). We suppose that this phenomenon represents an early positive reaction. For the present study, however, these findings were considered as a negative reaction increased pulmonary pressure associated with ethanol intake. The intensity of this damage is, however, lower than the one observed in case of fatal acute pulmonary hypertension, and this is probably due to the fact that the increase of pulmonary pressure is related to vascular constriction and is not related to a physical obstruction of the pulmonary circle as in cases of pulmonary embolism.

The reaction with the antibody against the terminal complement complex C5b-9 turned out negative in most cases. The different reaction patterns of the investigated antibodies can be probably explained because of the different times needed after cardiac insult to show positive reactions $[14,22]$. In some cases, in every investigated group, little brownish granulations could be detected at the surface of the cardiomyocytes at high magnification (Fig. 1d) with the antibody against C5b-9. We think that this phenomenon represents a beginning positive reaction. In the literature, however, we could not find any confirmation of this hypothesis, so that we systematically considered these reactions as negative.

In conclusion, the results of this research show that fresh cardiac damage can be detected at both ventricles in cases of fatal ethanol intoxication with the antibody against fibronectin. The damage is prevalently localised at the right ventricle, as already observed in cases of acute pulmonary hypertension determining right heart failure. Our results correspond to experimental data describing an increase of pulmonary pressure under the influence of ethanol. The degree of damage at the RV in cases of ethanol intoxication is lower than the one observed in cases of fatal PE.

These results have an important medicolegal relevance as they represent a morphological sign of acute sufferance of the right ventricle that may help in completing the diagnostic process of acute and fatal ethanol poisoning. This may be especially useful in those cases in which the blood ethanol levels are not extremely high and the question on the actual lethality of the ethanol poisoning arises. 


\section{References}

1. Saukko P, Knight B (2004) Modes of death in acute alcoholism. In: Saukko P, Knight B (eds) Knight's forensic pathology, 3rd edn. Arnold, London, p 557

2. Dmochowski A (1978) Die Äthylalkoholvergiftung. Krim forens Wiss 32:79-82

3. Kringsholm B (1976) Akute tödliche Alkoholvergiftung. Z Rechtsmed 78:313-319

4. Huckenbeck W, Bonte W (2004) Die tödliche Alkoholvergiftung. In: Madea B, Brinkmann B (eds) Handbuch gerichtliche Medizin, Band 2. Springer, Berlin, pp 425-427

5. Dixon WE (1907) The action of alcohol on the circulation. J Physiol 35:346-366

6. Doekel RC, Weir EK, Looga R, Grover RF, Reeves JT (1978) Potentiation of hypoxic pulmonary vasoconstriction by ethyl alcohol in dogs. J Appl Physiol 44:76-80

7. Kettunen R, Timisjärvi J, Saukko P, Koskela M (1983) Influence of ethanol on systemic and pulmonary hemodynamics in anesthetized dogs. Acta Physiol Scand 118:209-214

8. Kettunen R, Timisjärvi J, Saukko P (1992) The acute dose-related effects of ethanol on right ventricular function in anesthetized dogs. Alcohol 9:149-153

9. Drummond WH, Gause GE, Polak MJ, Lyles D, Cassin S (1989) Ethanol induces acute pulmonary vasoconstriction in salt-perfused rat lungs. Exp Lung Res 15:447-458

10. Koskinen P, Kupari M, Nieminen MS, Suokas A, Tötterman K, Pajari R, Heikkilä J (1986) Effects of alcohol on systemic and pulmonary hemodynamics in normal humans. Clin Cardiol 9:479482

11. Fracasso T, Karger B, Pfeiffer H, Sauerland C, Schmeling A (2010) Immunohistochemical identification of prevalent right ventricular ischemia causing right heart failure in cases of pulmonary fat embolism. Int J Leg Med. doi:10.1007/s00414009-0382-3
12. Fracasso T, Pfeiffer H, Sauerland C, Schmeling A (2010) Morphological identification of right ventricular failure in cases of fatal pulmonary thromboembolism. Int $\mathrm{J}$ Leg Med. doi:10.1007/s00414-010-0486-9

13. Brinkmann B, Sepulchre MA, Fechner G (1993) The application of selected histochemical and immunohistochemical markers and procedures to the diagnosis of early myocardial damage. Int J Leg Med 106:135-141

14. Ortmann C, Pfeiffer H, Brinkmann B (2000) A comparative study on the immunohistochemical detection of early myocardial damage. Int J Leg Med 113:215-220

15. Bemis CE, Serur JR, Borkenhagen D, Sonnenblick EH, Urschel CW (1973) Influence of right ventricular filling pressure on left ventricular pressure and dimension. Circ Res 34:498-504

16. Tool EW, Mullins CB, Leshin SJ, Mitchell JH (1974) Dimensional changes on the left ventricle during acute pulmonary arterial hypertension in dogs. Am J Cardiol 33:868-875

17. Laver MB, Strauss W, Pohost GM (1979) Right and left ventricular geometry: adjustments during acute respiratory failure. Crit Care Med 7:509-519

18. Lowensohn HS, Khouri EM, Gregg DE, Pyle RL, Patterson RE (1976) Phasic right coronary artery blood flow in conscious dogs with normal and elevated right ventricular pressures. Circ Res 39:760-766

19. Gold FL, Bache RJ (1982) Transmural right ventricular blood flow during acute pulmonary artery hypertension in sedated dog. Circ Res 51:196-204

20. Fracasso T, Pfeiffer H, Michaud K, Köhler H, Sauerland C, Schmeling A (2010) Immunohistochemical expression of fibronectin and C5b-9 in the myocardium in cases of carbon monoxide poisoning. Int J Leg Med. doi:10.1007/s00414-010-0512-y

21. Kapustin AV (1982) Diagnostische Bedeutung der Veränderung der Herzmuskelfasern beim Tod durch ischämische Herzerkrankung und akute Alkoholvergiftung. Krim forens Wiss 45:45-50

22. Thomsen H, Held H (1994) Susceptibility of C5b9 to post-mortem changes. Int J Leg Med 106:291-293 